\title{
EFFECT OF AMINDARONE INDUCED HYPER THYRIODISM ON BONE REMODELING PROCESS: HISTOLOGICAL AND RADIODENSITOMETRIC ANALYSIS. (EXPERIMENTAL STUDY IN RATS)
}

\author{
Inass Abdel Rahman Aboulmagd* and Samah Mohamed Kamel**
}

\begin{abstract}
Objectives: The aim of the study was to evaluate the effect of Amindarone drug alone and in combination with cabbige on bone methabolism on both histological and radiographical .

Subjects\& Methods: 15 rats were allocated in three groups, in group (I) the rats received the amiodarone, group (II) rats received aminodarone and uncooked cabbage while group(III) serve as a control group, by the end of $13^{\text {th }}$ week the rats were sacrified using an overdose of I.V. Phenobarbital.mandibles of the rats were subjected to histological and radiograghic examination .

Results: on the radiographic examination of the rats' mandible in group I that received the Amiodaron the bone density showed decrease with average of $(601 \pm 203)$ while in group II that received the Amiodaron and cabbages showed less decrease in bone density with average of (730 \pm 160.4$)$ than the control group (group III) that showed average of bone density of $(830 \pm 139.5)$ there is a significant difference among the groups $\mathrm{P}<0.001$.
\end{abstract}

Conclusion: Amiodarone drug induced the hyperthyroidism in rats treated for 13 weeks. The use of un cooked cabbage decrease the changes in the bone in both histological and radiographic evaluations

KEY WORDS: Amindarone, hyper thyriodism, Computed tomography, CT Bone density.

\section{INTRODUCTION}

Amiodarone is used as antiarrhythmic drug worldwide due to its effective role in treating supraventricular and ventricular tachyarrhythmias. It affects both myocardial depolarization and repolarization; moreover, its main antiarrhythmic action is through blockading potassium channel. In addition, Moreover amiodarone also acts by blockading sodium channel. $^{(1)}$ Despite its interesting profile as an antiarrhythmic agent, its use is hampered by a number of unwanted side effects, including thyroid dysfunction. ${ }^{(2-5)}$

* Lecturer, Department of Oral Radiology, Faculty of Dentistry, Fayoum University

** Lecturer, Department of Oral Biology, Faculty of Dentistry, October University of Modern Sciences and Art 
Amiodarone's influence on the production and secretion of T4 and T3 is multifactorial. Most evidently, each $200 \mathrm{mg}$ tablet of amiodarone contains $74.4 \mathrm{mg}$ of iodine by weight with $7.4 \mathrm{mg}$ per day being released as free iodine. ${ }^{(6)}$ This is 50 times more than the daily recommended iodine intake for adults; which is around $0.15 \mathrm{mg} .{ }^{(7)}$ This suggests that amiodarone use in the first 3 months leads to an increase in iodine delivery and uptake that in turn could raise thyroid hormone production and release. This is a condition called amiodarone induced thyrotoxicosis (hyperthyroidism). ${ }^{(8-10)}$ amiodarone induced thyrotoxicosis is more likely to occur in patients who live in areas of depressed iodine intake or have some type of underlying thyroid disease ${ }^{(11)}$

Thyroid hormones play an important role in linear development of the skeleton. They are essential to reach maximum bone mass ${ }^{(12)}$. However, the excess production of thyroid hormones in childhood might lead to premature growth of the plates and cranial sutures and finally short stature and craniosynostosis ${ }^{(12-15)}$. Whereas in adults, hyperthyroidism leads to an increase of bone turnover and loss of $10-20 \%$ of mineral density, mainly in cortical bone ${ }^{(12,13,15)}$. The cycle of bone remodeling is shortened to almost the half (from 200 to 113 days), and the rations between bone formation and bone resorption are changed ${ }^{(16)}$. The stage of bone formation is reduced to two thirds, which leads to the loss of over $10 \%$ of mineralized bone in one cycle. As a result, thyrotoxicosis will

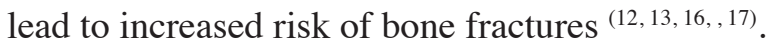

Studies showed many results of the reversibility of bone density that changed with respect to different types of treatment. These changes in bone metabolism are linked to negative calcium balance, hypercalciuria, and, rarely, hypercalcaemia ${ }^{(18,19)}$. Many nutritional factors assist in optimizing thyroid function. Unfortunately, both nutrient deficiencies and excesses can trigger or deteriorate symptoms

Cruciferous vegetables such as broccoli, Brussels sprouts, cabbage, cauliflower, Chinese cabbage ${ }^{(20)}$ are an excellent wellspring of sulfur- containing compounds called glucosinolates. Glucosinolates and their breakdown offshoots especially isothiocyanates and indole-3-carbinol, exert a variety of biological activities that may be significant to wellbeing and disease prevention in humans ${ }^{(21)}$

Cruciferous vegetables have high portions of isothiocyanates and goitrogens. These two substances help prevent the thyroid gland from overproducing thyroid hormone. However, very high intakes of cruciferous vegetables, such as cabbage and turnips, have been found to cause hypothyroidism in animals ${ }^{(22)}$.

Two mechanisms might explain this effect. The hydrolysis of progoitrin, found in cruciferous vegetables, produces a compound known as goitrin, which may cause disturbance to thyroid hormone synthesis. The hydrolysis of another class of glucosinolates, known as indole glucosinolates, leads to the release of thiocyanate ions that can rival with iodine for uptake by the thyroid gland. ${ }^{(23)}$

One study in humans concluded that the uptake of $150 \mathrm{~g} /$ day of cooked Brussels sprouts for a span of four weeks had no negative influences on thyroid function ${ }^{(24)}$. This was linked with the fact that heating cruciferous vegetables denatures much or all of this probable goitrogenic effect. ${ }^{(25)}$

The aim of the present study was to evaluate the effect of Amiodarone drug alone and in combination with cabbage on bone metabolism both histologically and radio- graphically in rats

\section{MATERIALS AND METHODS}

\section{Animal Model}

Fifteen healthy adult male Albino rats, three months old and 200-220 gm body weight were used in this study. The rats were obtained from Kasr el Aini animal experimental unit, Faculty of Medicine, Cairo University. The rats were housed in separate cages, five rats per cage and kept in an environment with controlled temperature $\left(27^{\circ} \mathrm{C}\right)$ 
and photo-period (12/12 hour light-dark cycle). The animals were fed with a natural diet and supplied with drinking water adlibitum throughout the whole present experiment. The rats were acclimatized for one week before the initiation of the experiment.

The animals were randomly allocated into one of three groups as follows:

Group I: consisted of 5 rats subjected to induction of hyperthyroidism using Amiodarone (Cordarone) Global NAPI pharmaceuticals $6^{\text {th }}$ October,Giza,Egypt with the following protocol:

Animals received amiodarone $(120 \mathrm{mg} / \mathrm{kg} /$ day) for 13 weeks. ${ }^{(26)}$ The doses of amiodarone were selected on the basis of the equivalent dose conversion coefficients between human and animal body surface area and our preliminary laboratory tests. Rats were monitored each morning for movement, breathing rate, fur condition, and signs of normal defecation.

Group II: Consisted of 5 rats treated as group II animals and at the same day they were fed $250 \mathrm{gm} /$ day un cooked cabbages for 13 weeks.

Group III: consisted of 5 rats and served as control. and receive no treatments.

At the end of the experiments, the animals of the whole groups were sacrificed for histologic and radiologic assessment using an overdose of I.V. Phenobarbital.

\section{Plasma assay :}

Blood was collected from the caudal vein of fasted rats (group I \& II) by at the end of week 13, $\mathrm{T} 3$ and $\mathrm{T} 4$ were measured to ensure that the rates in both groups developed hyperthyroidism

\section{Radiological Evaluation:}

The mandibles were dissected ,defleshed and scanned using Toshiba Asteion 4CT scanner with the following parameters: Tube voltage $120 \mathrm{Kvp}$, Milliampere $200 \mathrm{mAs}$, Voxel size $0.08 \mathrm{~mm}$, scanning time 750 seconds, Gantry tilt 0.00 , focal spot size $0.5 \mathrm{~mm}$ and 14 Bit gray scale resolution.
A scout view was obtained and adjustments were made to ensure that all samples were correctly aligned in the scanner according in the adjustment light beam before acquisition.

After acquisition, data were exported and transferred in DICOM formate and downloaded via a compact Disk (CD) to personal computer for analysis, where, OnDemand 3d App software (Cybermed, South Korea) was utilized density reading.

\section{Histologic preparation:}

Samples of the mandible were fixed with $10 \%$ neutral formalin, embedded in paraffin after decalcification, and stained with Hematoxylin and Eosin (H\&E) as a Routine stain for cellular details. Furthermore, Masson's trichrome stain was used for differentiation of mineralized and non-mineralized areas in the bone. The sections were observed under a light microscope (Olympus BX61, Hamburg, Germany) connected to a high-resolution digital camera (Olympus, E330, Imaging Corp).

\section{Statistical analysis:}

Data were fed to the computer and analyzed using IBM SPSS software package version 20.0. Quantitative data were explored for normality using Kolmogorov-Smirnov and Shapiro-Wilk tests. All data showed parametric distribution. Data were presented as mean and standard deviation (SD) values. To test the significance of observed differences between the study groups, a two-tailed homoscedastic t-test was applied. A value of $\mathrm{p}<$ 0.05 was considered to be statistically significant.

\section{RESULTS}

\section{Histological \& histochemical results}

In sections stained with $\mathrm{H} \& \mathrm{E}$ stain, the bone of mandibles in Group I revealed massive resorption due to induction of hyperthyroidism as the haversian structure was lost, the resorbed bone was replaced by fibrous tissue and large islands of osteoid tissues (Fig.1) 


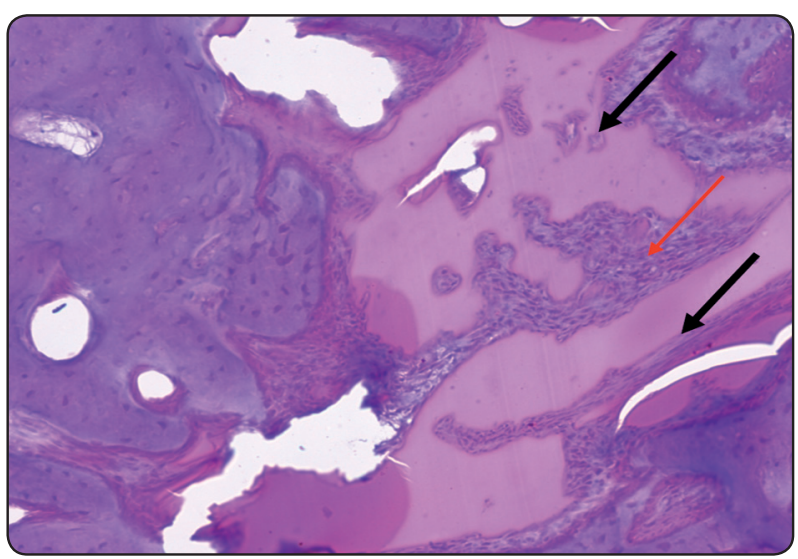

Fig. (1) Photomicrograph of the group I, it is evident that compact bone is resorbed and osteoid tissues are formed for healing (black arrow) scattered fibrous tissue is also noticed ( red arrow) (H\&E X200)

While In group II, the bone of mandibles of the rats that received the drug and had uncooked cabbages for 13 weeks showed intact haversian systems with small areas of resorption healed by small islands of osteoid; the rate of bone resorption is less than group 2 . ( Fig.2)

Furthermore, in Group III showed normal architecture of the compact bone, haversian canals surrounded by the osteocytes (Fig.3)

Regarding Goldner's Masson Trichrome stain, the mineralization of the bone of group I was massively decreased, the bone stained red and with small areas of green or blue stain revealing normal mineralization in small areas (Fig. 4)

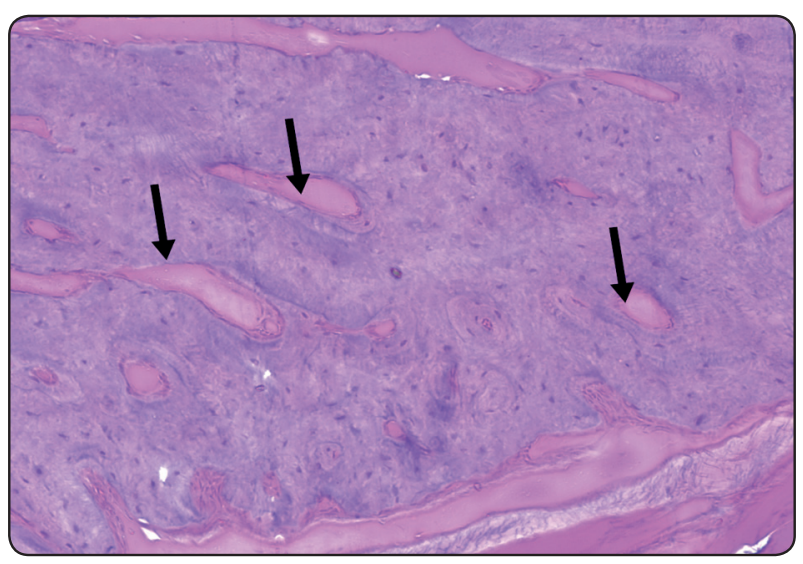

Fig. (2) photomicrograph of the group II, no fibrous tissues are found, separate small islands of osteoid tissues are noticed (black arrow) (H\&E X200)

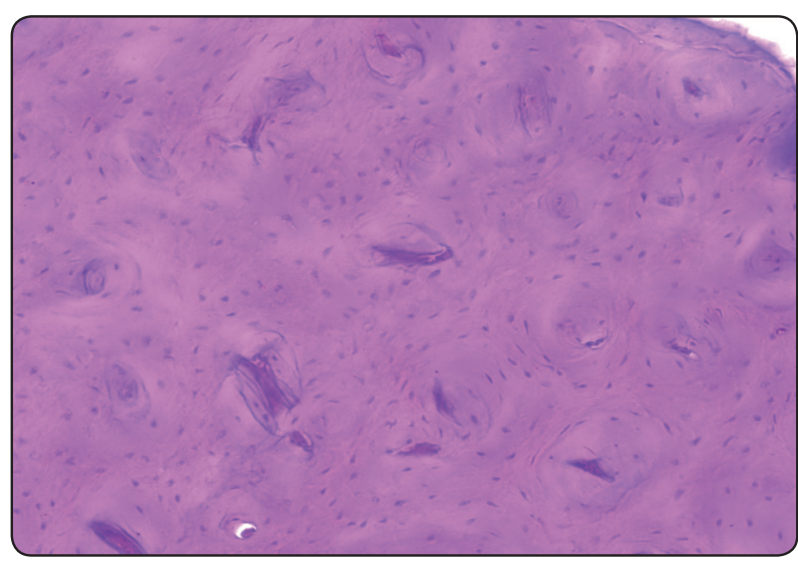

Fig. (3) Photomicrograph of control group showing normal compact bone with well-formed haversian systems (H\&E X200)

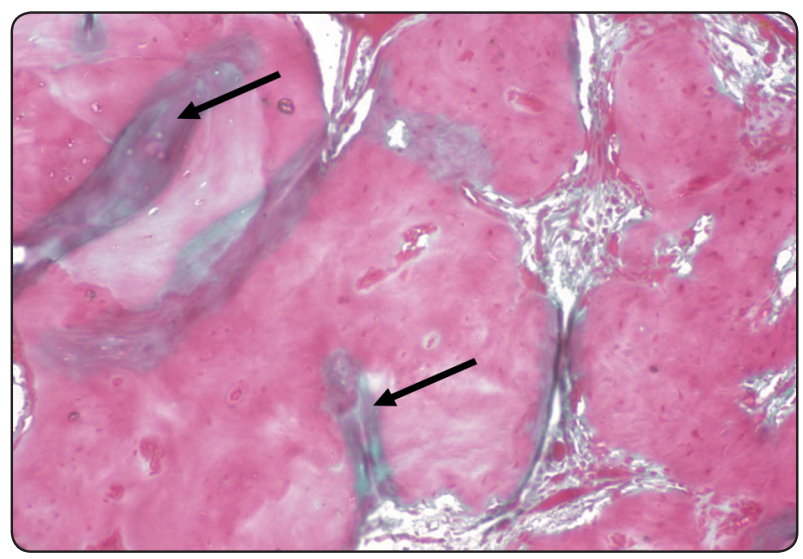

Fig. (4) photomicrograph of the group I, small areas of calcifications are noticable (black arrow) (Masson X200)

Group 3 showed mineralized mature bone stained blue or green, small areas of un-mineralized new immature bone stained red. (Fig.5) Calcification was less when compared to control group (Fig. 6) but much more than group 1

\section{Radiographic and statistical results}

On the radiographic examination of the rat mandible in group I that received the Amiodarone, the bone density showed a decrease with an average of $(601 \pm 203)$. Group II which received the Amiodaron and cabbages showed less decrease in bone density with average of $(730 \pm 160.4)$ than the control group (group III) that showed an average bone density of $(830 \pm 139.5)$ (fig.7 \& 8, table 1$)$ 


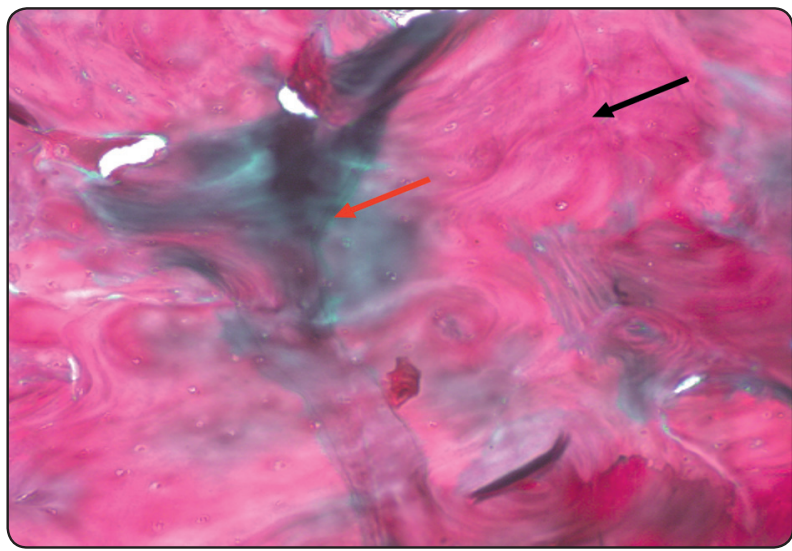

Fig. (5) Photomicrograph of the group II, mature bone with calcification less than group 1 but more than group 1, calcification (red arrow), immature bone ( black arrow) (Masson X200)

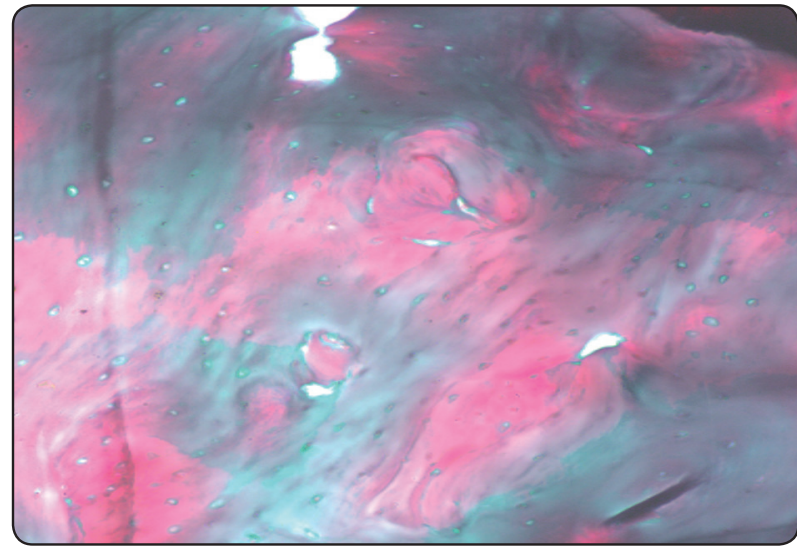

Fig. (6) photomicrograph of control group showing normal compact bone with normal calcification (Masson X200)

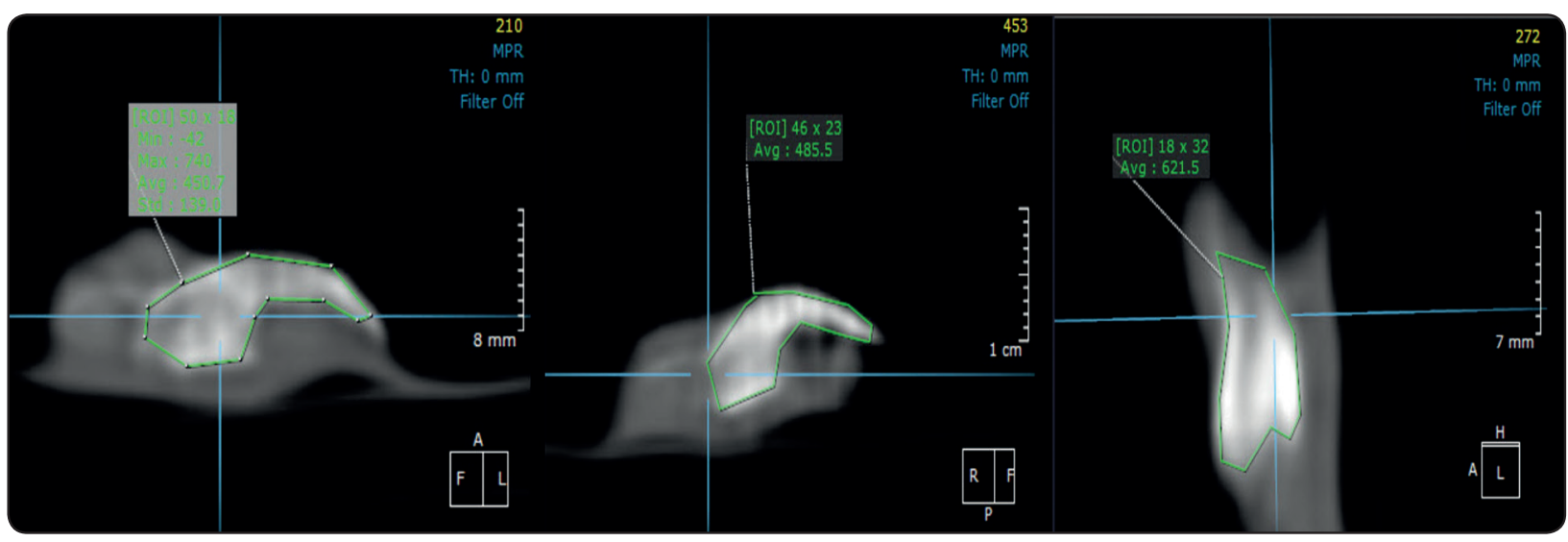

Fig. (7) CT sections of rat's mandible that showed the difference on bone density between the 3 groups

TABLE (1) Comparison between the bone density in the 3 groups

\begin{tabular}{|c|c|c|c|c|}
\hline & $\begin{array}{c}\text { Group I } \\
(\mathrm{n}=7)\end{array}$ & $\begin{array}{c}\text { Group II } \\
(\mathrm{n}=7)\end{array}$ & $\begin{array}{c}\text { Group III } \\
(\mathrm{n}=7)\end{array}$ & p-value \\
\hline $\begin{array}{c}\text { Bone } \\
\text { density }\end{array}$ & $601 \pm 203$ & $730 \pm 160.4$ & $830 \pm 139.5$ & $<0.001 *$ \\
\hline
\end{tabular}

Qualitative data were described using number and percent, while normally quantitative data was expressed in mean $\pm S D$, abnormally distributed data was expressed in median (Min. - Max.)

*: Statistically significant at $p \leq 0.05$

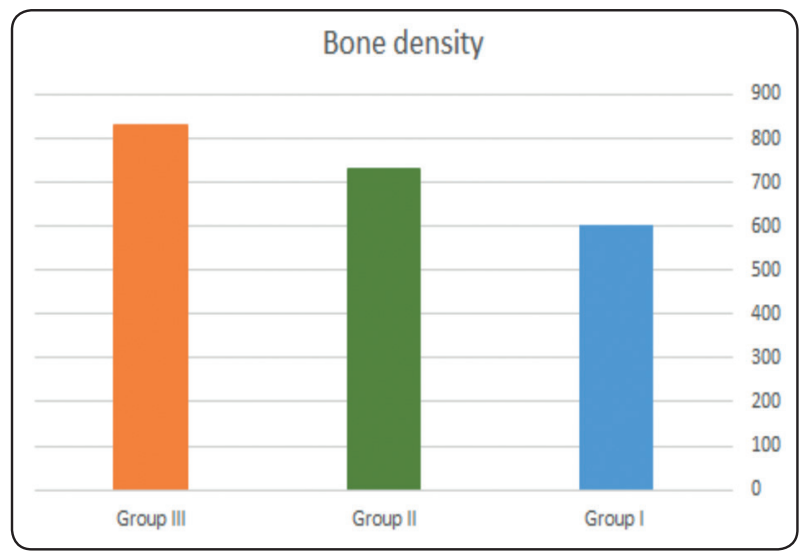

Fig. (8) Chart the showed the difference in bone density between the 3 groups. 


\section{DISCUSSION}

Amiodarone is a commonly recommended medication for the containment of both atrial and ventricular arrhythmias. The effects of amiodarone on the thyroid have been ascribed to its iodine content and intrinsic properties. ${ }^{(27)}$ Amiodarone is a ben-zofuran derivative containing $37.5 \%$ iodine by weight. Chronic treatment with amiodarone has been linked with a forty-fold increase in plasma and urinary iodide levels, which are responsible for thyroid dysfunction. This increase in iodine delivery and uptake can increase thyroid hormone production and release. This is a condition called amiodarone induced thyrotoxicosis (hyperthyroidism). ${ }^{(28)}$

In the present study when animals received amiodarone $(120 \mathrm{mg} / \mathrm{kg} / \mathrm{day})$ for 13 weeks they suffered from hyperthyroidism, many studies supported this, while some other studies found that Amiodarone causes hypothyroidism. The exact incidences of amiodarone-induced hyperthyroidism and amiodarone-induced hypothyroidism currently remain unknown; however, the reported frequencies of amiodarone-induced hyper-thyroidism and amiodarone-induced hypothyroidism vary widely from $0.8 \%$ to $37.8 \%{ }^{(29-32)}$

In our present study, the bone density of Group I was decreased with an average of $25 \%$ that is in accordance with the study of Basset et al, whom found in their study that hyperthyroidism caused loss of $10-20 \%$ of bone density in adults ${ }^{(12)}$

Stevens et al and Konsinska et al studied the effect of thyrotoxicosis \& hyperthyroidism on the bone remodeling process, they found that they disturb the ratio between bone formation and bone resorption. Our study supports their results histologically and histochemically as bone resorption was much more in group I than the other groups. ${ }^{(15)}$

In our study, radiographic, histological and histochemical results of group II showed relatively normal bone density and normal remodeling process due cabbage intake, raw cabbages decreased the effect the amiodarone on the thyroid gland.
Sharma et al found in their study that naturally occurring goitrogens, which are found in legumes and cabbages, can also affect the thyroid by interfering with thyroid hormone action ${ }^{(33)}$.Felker et al also supported this as raw, boiled and cooked extracts of various cyanogenic plant foods, including cauliflower and cabbage, have been shown to possess anti-Throidal activity. ${ }^{(23)}$

Jagminder $\mathrm{K}$. et al found that the goitrogenic potential of a plant or food depends upon the amount of active goitrogen present in it. Various procedures like soaking, washing, boiling and cooking can help in reducing the goitrogenic potency of these foods ${ }^{(34)}$

On the other hand, McMillan M et al concluded that the consumption of $150 \mathrm{~g} /$ day of cooked cyanogenic plant food for four weeks had no effects on thyroid function ${ }^{(24)}$

\section{CONCLUSION}

Amiodarone drug induced the hyperthyroidism in rats treated for 13 weeks. The use of un cooked cabbage decrease the changes in the bone in both histological and radiographic evaluations

\section{Clinical implication:}

Patients suffering from hypothyroidism should avoid consumption of raw cruciferous vegetables such as cabbage, Brussels sprouts, broccoli and cauliflower. It is difficult to prove the role of environmental chemicals in increasing susceptibility to thyroid dysfunction, although they have been blamed for its causation since long. Further studies on environmental toxicants are needed for viewing the impacts of these agents.

\section{REFERENCE}

1. Singh, B.N. (2008) Amiodarone as paradigm for developing new drugs for atrial fibrillation. J Cardiovasc Pharmacol 52: 300305 .

2. Papiris, S.A., Triantafillidou, C., Kolilekas, L., Markoulaki, D. and Manali, E.D. (2010) Amiodarone: Review of pulmonary effects and toxicity. Drug Saf 33: 539558. 
3. Van Erven, L. and Schalij, M.J. (2010) Amiodarone: An effective antiarrhythmic drug with unusual side effects. Heart 96: 15931600.

4. Vassallo, P. and Trohman, R.G. (2007) Prescribing amiodarone: An evidence-based review of clinical indications. JAMA 298: 13121322.

5. Bongard, V., Marc, D., Philippe, V., Jean-Louis, M. and Maryse, L.M. (2006) Incidence rate of adverse drug reactions during long-term follow-up of patients newly treated with amiodarone. Am J Ther 13: 315319.

6. Rao RH, McCready VR, Spathis GS. Iodine kinetic studies during amiodarone treatment. J Clin Endocrinol Metab 1986;62:563-8.

7. United States Department of Agriculture (USDA). Dietary reference intakes: elements. Last accessed on $1 / 2$

8. Claxton S, Sinha SN, Donovan $\mathrm{S}$ et al. Refractory amiodarone-associated thyrotoxicosis: an indication for thyroidectomy. Aust N Z J Surg 2000; 70:174-8.

9. Bartelena L, Grasso L, Brogioni S et al. Serum interleukin-6 in amiodarone-induced thyrotoxicosis. J Clin Endocrinol Metab 1994;78:423-7.

10. Bartelena L, Brogioni S, Grasso L et al. Treatment of amiodarone-induced thyrotoxicosis, a difficult challenge: results of a prospective study. J Clin Endocrinol Metab 1996;81:2930-3.

11. Basaria S, Cooper DS. Amiodarone and the thyroid. Am J Med 2005;118:706-14.

12. Basset J, Williams G: The molecular actions of thyroid hormone in bone. Trends Endocrinol Metab 2003, 14:356-364.

13. Harvey C, O'Shea P, Scott A, Robson H, Siebler T, Shalet S, Samarut J, Chassande O, Williams G: Molecular mechanisms of thyroid hormone effects on bone growth and function. Mol Genet Metab 2002, 75:17-30

14. Basset J, Williams G: Critical role of the hypothalamicpituitary-thyroid axis in bone. Bone 2008, 43:418-426

15. Stevens D, Harvey C, Scott A, Williams A, Jackson D, O'Shea P, Williams G: Thyroid hormone activates fibroblast growth factor receptor-1 in bone. Mol Endocrinol 2003, 17:1751-1766

16. Kosińska A, Syrenicz A, Kosiński B, Garanty-Bogacka B, Syrenicz M, Gromiak E: Osteoporoza w chorobach tarczycy. Endokrynol Pol 2005, 2:185-193.

17. Lakatos P: Thyroid hormones: beneficial or deleterious for bone? Calcif Tissue Int 2003, 73:205-209.
18. Mosekilde L, Eriksen EF, Charles P. Effects of thyroid hormones on bone and mineral metabolism. Endocrinol Metab Clin North Am. 1990;19:35-63

19. Frizel D, Malleson A, Marks V. Plasma levels of ionised calcium and magnesium in thyroid disease. Lancet. 1967;I:1360-1.

20. International Agency for Research on Cancer. Cruciferous vegetables. Cruciferous vegetables, isothiocyanates and indoles. Lyon, France: IARC; 2004:1-12.

21. Steinbrecher A, Linseisen J. Dietary intake of individual glucosinolates in participants of the EPIC-Heidelberg cohort study. Ann Nutr Metab. 2009;54(2):87-96.

22. Fenwick GR, Heaney RK, Mullin WJ. Glucosinolates and their breakdown products in food and food plants. Crit Rev Food Sci Nutr. 1983;18(2):123-201.

23. Felker P, Bunch R, Leung AM. Concentrations of thiocyanate and goitrin in human plasma, their precursor concentrations in brassica vegetables, and associated potential risk for hypothyroidism. Nutr Rev. 2016;74(4):248-258.

24. McMillan M, Spinks EA, Fenwick GR. Preliminary observations on the effect of dietary brussels sprouts on thyroid function. Hum Toxicol. 1986;5(1):15-19.

25. Rungapamestry V, Duncan AJ, Fuller Z, Ratcliffe B. Effect of cooking brassica vegetables on the subsequent hydrolysis and metabolic fate of glucosinolates. Proc Nutr Soc. 2007;66(1):69-81.

26. Li-Qin Jianga Shan-Jiang Chenb Jian-Jiang Xua Zhang Rana Wang Yinga Sheng-Gang Zhaoa. Dronedarone and Amiodarone Induce Dyslipidemia and Thyroid Dysfunction in Rats. Cellular Physiology and Biochemistry. 2016;38:2311-2322

27. Daniels GH. Amiodarone-induced thyrotoxicosis. J Clin Endocrinol Metab 2001;86:3-8.

28. Rao RH, McCready VR, Spathis GS. Iodine kinetic studies during amiodarone treatment. J Clin Endocrinol Metab 1986;62:563-8.

29. Shiga T, Wakaumi M, Matsuda N, et al. AmiodaroneInduced thyroid dys-function and ventricular tachyarrhythmias during long-term therapy in Japan. Jpn Circ J 2001;65:958-60.

30. Ahmed S, Van Gelder IC, Wiesfeld AC, et al. Determinants and outcome of amiodarone-associated thyroid dysfunction. Clin Endocrinol 2011;75:388-94. 
31. Lee KF, Lee KM, Fung TT. Amiodarone-induced thyroid dysfunction in the Hong Kong Chinese population. Hong Kong Med J 2010;16:434-9.

32. Zosin I, Balas M. Amiodarone-induced thyroid dysfunction in an iodine-replete area: epidemiological and clinical data. Endokrynol Pol 2012;63:2-9.
33. Sharma RB, Burek CL, Cihakova D, Njoku DB, Rose NR. Environmental factors in autoimmune endocrinopathies. In: Weetman AP, Editor. Autoimmune diseases in Endocrinology. Totowa NJ: Humana Press; 2008.pp.35-75.

34. Jagminder KB, Poonam S., Shalini S., Various Possible Toxicants Involved in Thyroid Dysfunction: A Review. JCDR 2016;15195.7092 